ISSN 1980-5098 @®@ DOI: http://dx.doi.org/10.5902/1980509831590

\title{
VARIÁVEIS-CHAVE PARA DETERMINAÇÃO DA QUALIDADE DA ÁGUA EM MICROBACIAS COM PLANTIOS DE EUCALIPTO
}

\author{
KEY VARIABLES TO DETERMINATE THE WATER QUALITY IN WATERSHEDS WITH \\ EUCALYPTUS PLANTATIONS
}

\author{
Benvindo Sirtoli Gardiman Junior ${ }^{1}$ Giovanni de Oliveira Garcia ${ }^{2}$ Roberto Avelino Cecílio ${ }^{3}$ \\ Rodolfo Araújo Loos ${ }^{4}$ Reginaldo Gonçalves Mafia ${ }^{5}$ Jupiter Israel Muro Abad ${ }^{6}$ \\ João Batista Pavesi Simão ${ }^{7}$ Vitor Hugo Breda Barbosa ${ }^{8}$
}

\begin{abstract}
RESUMO
O presente trabalho objetivou identificar as principais variáveis afetadas por fatores naturais e, ou, antrópicos, que influenciam a qualidade da água superficial em microbacias hidrográficas, manejadas para produção de madeira de eucalipto. A qualidade da água foi monitorada em quatro microbacias localizadas no município de Aracruz, norte do ES, Brasil. Para tanto, analisaram-se as características físicas e químicas, bem como a potencial presença na água de agrotóxicos utilizados no manejo florestal. As coletas foram realizadas após as atividades silviculturais e/ou ocorrência de chuvas entre os meses de janeiro e junho de 2012. Foram utilizadas técnicas de componentes principais e análise fatorial para determinar as variáveis mais sensíveis e correlacionadas com as atividades silviculturais e com as condições edafoclimáticas das microbacias. De forma geral, 4 componentes explicaram $73,1 \%$ da variância total. Os componentes foram correlacionados com as variáveis analisadas e definidos como fatores: mineral, sólido, acidez e pedológico. Estes fatores explicaram 31,$6 ; 18,5 ; 15,6$; e 7,4\% da variância total dos dados e estão diretamente relacionados com a salinidade, a presença de sólidos suspensos, a acidez e o teor de carbono inorgânico do solo, respectivamente. Não foi observada presença dos agrotóxicos sulfluramida (inseticida) e glifosato (herbicida) em todas as avaliações realizadas. Em geral, é possível reduzir de 30 para 12 as variáveis que devem ser monitoradas para predição da qualidade da água, mantendo pelo menos $70 \%$ da precisão das estimativas. Palavras-chave: manejo florestal; hidrologia florestal; índice de qualidade da água; estatística multivariada.
\end{abstract}

\section{ABSTRACT}

This work aimed to identify the main variables affected by natural factors and, or anthropic, which influence the quality of surface water in watersheds, managed for eucalyptus wood production. Water quality was monitored in four watersheds located in Aracruz, northern ES state, Brazil. The physical and chemical

1 Engenheiro Ambiental, MSc., Professor do Instituto Federal de Ciência e Tecnologia do Espírito Santo, Campus Ibatiba, Av. Sete de Novembro, 40, CEP 29395-000, Ibatiba (ES), Brasil. benvindo.gardiman@ifes.edu.br

2 Engenheiro Agrônomo, Dr., Professor Adjunto do Departamento de Engenharia Rural, Universidade Federal do Espírito Santo, Alto Universitário, s/n, CEP 29500-000, Alegre (ES), Brasil. giovanni.garcia@ufes.br

3 Engenheiro Agrícola, Dr., Professor Associado do Departamento de Engenharia Florestal e da Madeira, Universidade Federal do Espírito Santo, Av. Governador Lindemberg, 316, CEP 29550-000, Jerônimo Monteiro (ES), Brasil. roberto.cecilio@ufes.edu

4 Engenheiro Agrônomo, Dr., Pesquisador em Ecofiologia Florestal na Fibria Celulose S/A, Rod. ES-257, km 25, Barra do Riacho, CEP 29197-900, Aracruz (ES), Brasil. raloos@fibria.com.br

5 Engenheiro Florestal, Dr., Coordenador de pesquisa em proteção florestal na Fibria Celulose S/A, Rod. ES-257, km 25, Barra do Riacho, CEP 29197-900, Aracruz (ES), Brasil. rgoncalves@fibria.com.br

6 Engenheiro Florestal, Dr., Gerente na empresa DEFORSA/PAVECA, Empresa Florestal e de Papel na Venezuela. jupiter.muro@paveca.com.ve

7 Engenheiro Agrônomo, Dr., Professor do Instituto Federal de Ciência e Tecnologia do Espírito Santo, Campus de Alegre, Distrito de Rive, CEP 29520-000, Alegre (ES), Brasil. jbpsimao@ifes.edu.br

8 Engenheiro Florestal, MSc.,Departamento de Engenharia Agrícola, Universidade Federal de Viçosa, Av. Peter Henry Rolfs, s/n, Campus Universitário, CEP 36.570-900, Viçosa (MG), Brasil. vitorhbb@yahoo.com.br

Recebido para publicação em 6/09/2015 e aceito em 15/08/2016

Ci. Fl., v. 28, n. 1, jan.- mar., 2018 
characteristics of the water and the potential presence of pesticides used in forest management were evaluated. Samples were collected after the silvicultural activities and, or, rainfall between the months of January to June 2012. Principal component and factor analysis techniques were used to determine the water variables most sensitive and correlated with forestry activities, soil and climatic conditions of the study watersheds. It was possible to obtain four components that explained $73.1 \%$ of the total variance. The components were correlated with the variables and defined as factors mineral, solid, acidity, and pedological. These factors explained $31.6 ; 18.5 ; 15.6$; and $7.4 \%$ of the total variance of the data which are directly related to salinity, the presence of suspended solids, acidity and the inorganic carbon content of the soil, respectively. Sulfluramid (insecticide) and glyphosate (herbicide) were not found. In general, it is possible to reduce from 30 to 12 variables that should be monitored for prediction of water quality, maintaining at least $70 \%$ of the precision of the estimates. The evaluation of these key variables allows establishing an adequate monitoring system of water quality considering the eucalyptus forestry activities. Keywords: forest management; forest hydrology; water quality index; multivariate statistics.

\section{INTRODUÇÃO}

Atualmente, a identificação de causas e dos efeitos relacionados com a degradação da qualidade da água tem sido extensivamente estudada, com o objetivo de estabelecer procedimentos de avaliação e mitigação dos impactos ambientais, bem como para adotar técnicas para aumento da produtividade florestal, consonante com a conservação dos recursos hídricos (MENEZES et al., 2009; GUIMARÃES et al., 2010). Logicamente, o manejo silvicultural ou agrícola inadequado pode causar impactos negativos para a qualidade e disponibilidade de água. Sendo assim, o monitoramento contínuo deste recurso natural, bem como o esforço de identificar e corrigir atividades que possam afetar sua qualidade é uma das formas de mitigação dos riscos (GUIMARÃES et al., 2008).

A qualidade da água é controlada por uma complexa relação entre o meio biótico e abiótico de uma bacia hidrográfica, sendo que qualquer perturbação que cause interferências significativas pode ser detectada quanto às características físicas e químicas dos cursos d'água (SLIVA; WILLIAMS, 2001; BUENO et al., 2005). Por outro lado, para a relação entre uso do solo e qualidade da água, existem vários fatores que podem interferir nas respostas, as quais ocorrem de forma dinâmica, o que dificulta a determinação de causa e efeito (BUENO et al., 2005; ANDRADE et al., 2007b). Por este motivo, a definição das variáveis de qualidade da água que devem ser monitoradas é de fundamental importância para geração de resultados que possam ser úteis para adequações, quando necessário, do manejo florestal (LIMA; ZAKIA, 2006).

A qualidade da água é resultante dos inúmeros processos que ocorrem na bacia de drenagem do corpo hídrico, sendo modificada por diversos fatores atuantes, estando relacionada diretamente com o uso e ocupação do solo, permitindo, muitas vezes, diagnosticar possíveis causas dos impactos ambientais sobre os recursos naturais (BRAGA et al., 2005; VON SPERLING, 2005). A análise dos efeitos ambientais das atividades de manejo pode ser quantificada, em maior grau de precisão, empregando microbacias hidrográficas com áreas reduzidas (menores que 50 hectares). Estas áreas, em função da sua conformidade espacial, permitem avaliar de forma mais direta e precisa o efeito das atividades desenvolvidas sobre a qualidade da água (GRAYSON et al., 1993; CÂMARA; LIMA, 1999; BUENO et al., 2005; GRACE, 2005; GUIMARÃES et al., 2010; SCHELKER et al., 2012). Nesse contexto, o objetivo deste traballho foi identificar as principais variáveis afetadas por fatores naturais e/ou antrópicos, que influenciam a qualidade da água superficial em áreas com manejo para produção de madeira de eucalipto.

\section{MATERIAL E MÉTODOS}

\section{Caracterização das microbacias hidrográficas}

O estudo foi desenvolvido em quatro microbacias hidrográficas (MBs) de cabeceira com plantios de eucalipto, situadas no município de Aracruz - ES, entre 19² $42^{\prime}$ S e $1^{\circ} 54^{\prime}$ ' S de latitude e entre $40^{\circ} 06^{\prime}$ e $40^{\circ} 14^{\prime} \mathrm{W}$ de longitude, com altitude variando entre 10 e 50 metros acima do nível do mar (Figura 1) e relevo 
plano a suavemente ondulado.

LOCALIZAÇÃo DA AREA DE ESTUDO

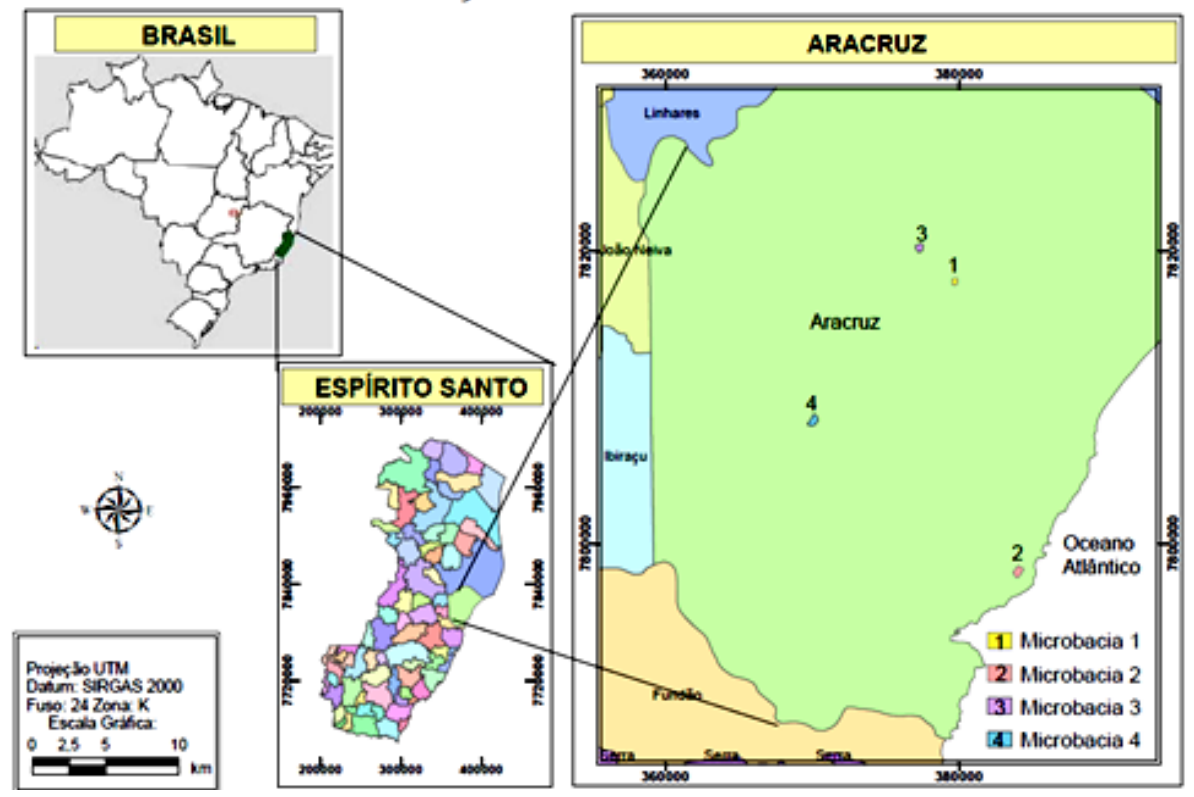

FIGURA 1: Localização da área de estudo em Aracruz, Espírito Santo, Brasil.

FIGURE 1: Location of the study area in Aracruz, Espírito Santo state, Brazil.

As MBs 1, 2, 3 e 4 possuem área de 16,09, 33,14, 21,65 e 31,95 hectares, respectivamente, e a ocupação de $70 \%$ cultivado com Eucalyptus grandis em diferentes estágios, passando da colheita ao plantio (Tabela 3), o restante com áreas de reserva legal, preservação permanente e carreadores. O clima da região segundo a classificação de Köppen é Aw, ou seja, tropical úmido, com estação chuvosa no verão e seca no inverno. A temperatura média anual é de $23^{\circ} \mathrm{C}$ e a precipitação média da região é de $1.200 \mathrm{~mm}$ anuais, concentrando-se entre outubro a março, quando ocorre de 65 a $80 \%$ do total de chuvas (ALVARES, 2013).

Os solos das MBs foram caracterizados quanto à textura em profundidades de 0-20 e 20-40 $\mathrm{cm}$, condutividade hidráulica e classificados de acordo com os aspectos físicos (EMBRAPA, 2000). A condutividade hidráulica dos solos foi determinada em pelo menos três pontos aleatórios e representativos. As medições foram realizadas a uma profundidade de $20 \mathrm{~cm}$ com o auxílio de um Permeâmetro de Guelph (Tabela 1).

TABELA 1: Tipo e caracterização física dos solos das microbacias. Aracruz - ES, Brasil.

TABLE 1: Type and physical characterization of the watershed soils. Aracruz - ES, Brazil.

$\begin{array}{cccccc}\text { Areia } & \text { Areia } & \text { Silte } & \text { Argila } & \text { Condutividade } \\ \text { Minas } & \text { Classe textural } & & \text { Classificação } & \text { hidráulica }\end{array}$

\begin{tabular}{|c|c|c|c|c|c|c|c|}
\hline & \multicolumn{4}{|c|}{----------------_\%----------------- } & & & $\mathrm{mm} \mathrm{h}^{-1}$ \\
\hline 1 & 44,54 & 21,79 & 8,79 & 24,89 & Arenosa-média & Argissolo Amarelo & 8,70 \\
\hline 2 & 41,82 & 17,83 & 5,52 & 35,14 & Média-argilosa & Argisolo Amarelo & 7,52 \\
\hline 3 & 43,40 & 19,60 & 8,00 & 29,00 & Média & Latsolo Amarelo & 8,07 \\
\hline 4 & 52,73 & 12,93 & 8,47 & 25,87 & Média-argilosa & Argissolo Amarelo & 9,18 \\
\hline
\end{tabular}

A caracterização química dos solos foi realizada por meio da coleta de amostras em duas profundidades, $0-20 \mathrm{~cm}$ e de $20-40 \mathrm{~cm}$. As amostras foram analisadas quanto aos seguintes parâmetros químicos: fósforo, potássio, cálcio, magnésio, acidez potencial $(\mathrm{H}+\mathrm{Al})$, matéria orgânica $(\mathrm{MO})$ e $\mathrm{pH}$. De 
posse dos valores acima foram calculados: soma de bases (SB); saturação de bases (V) e capacidade de troca catiônica a pH 7 (T), conforme apresentado na Tabela 2.

TABELA 2: Caracterização química ${ }^{1}$ dos solos das microbacias. Aracruz - ES, Brasil.

TABLE 2: Chemical characterization of the watersheds soils. Aracruz, ES state, Brazil.

\begin{tabular}{|c|c|c|c|c|c|c|c|c|c|c|}
\hline Microbacia & $P$ & K & $\mathrm{Ca}$ & $\mathrm{Mg}$ & $\mathrm{H}+\mathrm{Al}$ & $\begin{array}{l}\text { Soma } \\
\text { Bases }\end{array}$ & $\mathrm{T}$ & $\mathrm{V}$ & MO & $\mathrm{pH}$ \\
\hline & \multicolumn{2}{|c|}{$-m g \mathrm{dm}^{-3}-$} & \multicolumn{5}{|c|}{$-\mathrm{cmol}_{\mathrm{c}} \mathrm{dm}^{-3}-\mathrm{-}$} & $(\%)$ & dag kg-1 & \\
\hline 1 & 3,0 & 13,7 & 0,40 & 0,13 & 4,72 & 2,76 & 7,48 & 36,6 & 1,70 & 4,0 \\
\hline 2 & 15,0 & 16,6 & 0,61 & 0,18 & 3,17 & 4,11 & 7,28 & 56,4 & 1,65 & 4,1 \\
\hline 3 & 7,1 & 22,8 & 1,03 & 0,21 & 2,94 & 6,50 & 9,44 & 68,8 & 2,37 & 4,1 \\
\hline 4 & 7,7 & 12,7 & 1,03 & 0,14 & 3,92 & 5,89 & 9,81 & 60,0 & 2,20 & 4,1 \\
\hline
\end{tabular}

Em que: ${ }^{1}$ Valores médios de análises realizadas pela empresa Fibria Celulose $\mathrm{S} . \mathrm{A} . \mathrm{H}+\mathrm{Al}=$ acidez potencial; $\mathrm{T}=$ capacidade de troca catiônica a pH 7; V = saturação de bases; $\mathrm{MO}=$ matéria orgânica

\section{Monitoramento da qualidade da água nas microbacias hidrográficas}

O monitoramento das variáveis de qualidade da água superficial foi realizado durante os meses de janeiro a junho de 2012. As amostras de água foram coletadas no exutório das MBs 1 (um) dia após a realização das atividades silviculturais (Tabela 3 ) e eventos de chuvas, exceto na coleta de referência. Após as coletas, as amostras foram preservadas conforme procedimentos descritos na norma técnica ABNT NBR 9898 (1987). Os equipamentos utilizados bem como os métodos de detecção empregados seguiram os preceitos da American Public Health Association (AMERICAN PUBLIC HEALTH ASSOCIATION, 2005).

TABELA 3: Atividades silviculturais realizadas nas microbacias. Aracruz - ES, Brasil.

TABLE 3: Silvicultural activities carried out in the watersheds. Aracruz, ES state, Brazil.

\begin{tabular}{ccc}
\hline $\begin{array}{c}\text { Microbacia } \\
\text { Experimental }\end{array}$ & $\begin{array}{c}\text { Identificação da } \\
\text { atividade }\end{array}$ & Descrição das atividades silviculturais \\
\hline 1 & 1 & Referência (sem atividade de silvicultura e ocorrência de chuvas) \\
Abertura de estradas, colheita e transporte de madeira.
\end{tabular}


TABELA 3: Continuação...

TABLE 3: Continued...

\begin{tabular}{|c|c|c|}
\hline $\begin{array}{c}\text { Microbacia } \\
\text { Experimental }\end{array}$ & $\begin{array}{l}\text { Identificação da } \\
\text { atividade }\end{array}$ & Descrição das atividades silviculturais \\
\hline 3 & 13 & Capina química pós-plantio \\
\hline 3 & 15 & Adubação de cobertura \\
\hline 4 & 1 & Referência (sem atividade de silvicultura e ocorrência de chuvas) \\
\hline 4 & 7 & Colheita mecanizada \\
\hline 4 & 14 & $\begin{array}{l}\text { Primeiro controle de formigas-cortadeiras, capina química pré-plantio, } \\
\text { eliminação química da cepa, limpeza da linha de plantio, subsolagem com } \\
\text { adubação e plantio }\end{array}$ \\
\hline 4 & 5 & Roçada mecanizada \\
\hline
\end{tabular}

As variáveis de qualidade da água monitoradas foram: Cálcio $(\mathrm{Ca})$, Cobre $(\mathrm{Cu})$, Ferro $(\mathrm{Fe})$, Potássio $(\mathrm{K})$, Magnésio (Mg), Sódio (Na), Fósforo (P), Enxofre (S), Zinco (Zn), Carbono Inorgânico (CI), Carbono Orgânico (CO), Cloreto (Clor), Nitrato (Nitr), Sulfato (Sulf), Fosfato (Fosf), Amônio (Amo), Glifosato (Glif), Alcalinidade (Alca), Condutividade Elétrica (CE), Cor (Cor), Demanda Química de Oxigênio (DQO), Dureza do Cálcio, Dureza do Magnésio, Oxigênio Dissolvido (OD), Sólidos Suspensos (SS), Sólidos Dissolvidos (SD), Sulfluramida (Sulfl), Temperatura (Tem), Turbidez (Turb) e pH nas quatro MBs, representadas pelas abreviações entre parênteses.

O monitoramento da precipitação foi realizado por meio de estações meteorológicas automáticas localizadas a menos de 5 (cinco) quilômetros do ponto de amostragem das áreas do estudo.

\section{Análises estatísticas}

Os dados obtidos foram analisados por técnicas de estatística multivariada, incluindo análise de componentes principais e análise fatorial. Como as variáveis apresentam diferentes unidades de medida, antes de realizar as análises estatísticas, os dados foram correlacionados em matriz [R] em (p x p), sendo p o número de variáveis analisadas, utilizando-a posteriormente para proceder à análise de componentes principais e a análise fatorial, conforme Equação abaixo.

$$
R=\frac{1}{p-1}\left(D^{-1 / 2 * S D^{-1 / 2}}\right)
$$

Sendo $\mathrm{D}^{-1 / 2}$, a matriz diagonal ( $\mathrm{p}$ x p), em que $\mathrm{p}$ é o número de variáveis:

$S$ é o $X^{\prime}{ }_{d} X_{d}$

$\mathrm{S}$ é a matriz de covariância dos quadrados das médias padronizados;

$\mathrm{X}_{\mathrm{d}}$ é a matriz transposta de $\mathrm{X}_{\mathrm{d}}$, ;

$X_{d}$ é a matriz normatizada de dados.

As variáveis com coeficiente de determinação maior ou igual a 0,7 ou menores ou iguais a $-0,7$ foram selecionadas (HAIR JUNIOR et al., 2009). Sendo assim, a eficiência do novo modelo ficou dependente da variação total de cada componente principal, refletida nos autovalores. O método de Kayser Mayer Olkim (KMO) foi empregado para avaliar a adequação do conjunto de variáveis ao procedimento estatístico, a partir da matriz de correlação, conforme Equação a seguir:

$$
K M O=\frac{\sum_{i} \neq j \sum_{r_{i j}}{ }^{2}}{\sum_{i} \neq j \Sigma_{i j}{ }^{2}+\sum_{i} \neq j \sum a_{i j}{ }^{2}}
$$

Em que:

$\mathrm{r}_{\mathrm{ij}}$ é o coeficiente de correlação simples entre as variáveis i e j, e;

$a_{i j}$ é o coeficiente de correlação parcial entre as variáveis i e j. 
Após esta etapa, os componentes principais foram determinados a partir de uma combinação linear com variância máxima entre as variáveis, sendo no máximo igual ao número de variáveis (ANDRADE et al., 2007b), conforme Equação seguinte.

$$
f_{k}=\sum_{1}^{p} W_{k i} X_{i}=W_{k 1} X_{1}+W_{k 2} X_{2}+\ldots+W_{k p} X_{p}
$$

Em que:

$\mathrm{W}_{\mathrm{ki}}$ é o peso da $i$-ésima variável no $k$-ésimo fator;

Xi é o escore atribuído a cada variável, e;

p é o número de variáveis.

Os componentes principais com autovalor superior a 1,0 foram selecionados em número suficiente para explicar pelo menos $60 \%$ da variância acumulada (HAIR JUNIOR et al., 2009), de forma que qualquer componente possa explicar uma variância superior àquela apresentada por uma simples variável padronizada, que é igual a 1,0 (ANDRADE et al., 2007a). De posse da matriz de componentes, procedeu-se a rotação dos fatores com o objetivo de ajustar os eixos fatoriais. Utilizou-se a rotação Varimax normalizada, aproximando as cargas da matriz em 1,0 ou -1,0 e eliminando valores intermediários (GIRÃO et al., 2007; HAIR JUNIOR, 2009; LOPES et al., 2009). Posteriormente, as variáveis que apresentaram coeficiente de correlação maior ou igual a 0,7 e menor ou igual a $-0,7$ foram selecionadas dentro de cada um dos componentes principais. Empregou-se também a análise de comunalidade, que é a estimativa da variância compartilhada, ou em comum, entre as variáveis representadas pelos fatores obtidos (ANDRADE et al., 2005). Os valores obtidos mais próximos de 1,0 evidenciaram a obtenção de modelos mais ajustados (HAIR JUNIOR, 2009).

\section{RESULTADOS E DISCUSSÃO}

\section{Variáveis de qualidade da água e legislação}

A Tabela 4 apresenta os resultados das amostragens de qualidade da água analisadas nas quatro (4) microbacias hidrográficas estudadas e as atividades monitoradas. Os limites de cada variável estabelecido pela legislação encontram-se na linha inferior da referida Tabela.

TABELA 4: Resultado das variáveis de qualidade de água e intensidade máxima de precipitação (IP) em cada atividade monitorada nas microbacias hidrográficas (MB) estudadas.

TABLE 4: $\quad$ Results of water quality variables and maximum intensity of rainfall (IP) in each activity monitored in the studied watersheds (MB).

\begin{tabular}{|c|c|c|c|c|c|c|c|c|c|c|c|c|c|c|c|c|c|}
\hline \multirow[t]{2}{*}{$\mathrm{MB}$} & Ativ & $\mathrm{Ca}$ & $\mathrm{Cu}$ & $\mathrm{Fe}$ & $\mathrm{K}$ & $\mathrm{Mg}$ & $\mathrm{Na}$ & $\mathrm{P}$ & $\mathrm{S}$ & $\mathrm{Zn}$ & CI & $\mathrm{CO}$ & Clor & Nitr & Sulf & Fosf & Amo \\
\hline & & \multicolumn{16}{|c|}{ - } \\
\hline 1 & 1 & 0,07 & 0,01 & 0,58 & 0,55 & 1,83 & 10,70 & 0,00 & 0,93 & 0,00 & 1,95 & 3,53 & 14,40 & 0,71 & 1,94 & 0,00 & 0,08 \\
\hline 1 & 2 & 0,79 & 0,01 & 0,58 & 0,32 & 2,15 & 10,11 & 0,00 & 1,32 & 0,04 & 0,23 & 24,85 & 15,86 & 0,77 & 1,97 & 0,00 & 0,07 \\
\hline 1 & 3 & 0,76 & 0,01 & 1,46 & 0,32 & 1,92 & 10,82 & 0,01 & 1,71 & 0,01 & 0,83 & 34,88 & 17,79 & 0,74 & 2,71 & 0,00 & 0,07 \\
\hline 1 & 4 & 0,73 & 0,01 & 0,52 & 0,34 & 1,88 & 10,69 & 0,00 & 3,09 & 0,00 & 2,00 & 2,84 & 15,20 & 0,80 & 2,25 & 0,00 & 0,06 \\
\hline 2 & 1 & 2,46 & 0,00 & 1,06 & 0,51 & 3,38 & 12,94 & 0,00 & 5,97 & 0,00 & 1,21 & 15,48 & 18,17 & 0,63 & 10,4 & 0,00 & 0,24 \\
\hline 2 & 5 & 2,45 & 0,03 & 1,40 & 1,37 & 3,46 & 14,88 & 0,01 & 2,16 & 0,03 & 0,21 & 43,64 & 29,61 & 0,00 & 2,55 & 0,00 & 0,97 \\
\hline 2 & 4 & 0,98 & 0,02 & 2,44 & 1,56 & 3,01 & 14,59 & 0,02 & 2,73 & 0,00 & 0,33 & 47,35 & 27,35 & 0,00 & 5,62 & 0,00 & 1,34 \\
\hline 2 & 6 & 2,51 & 0,01 & 2,06 & 1,49 & 3,33 & 13,25 & 0,01 & 6,57 & 0,00 & 1,63 & 19,75 & 19,91 & 0,07 & 7,01 & 0,00 & 0,23 \\
\hline 2 & 7 & 4,22 & 0,02 & 3,65 & 1,14 & 3,67 & 13,21 & 0,04 & 2,68 & 0,01 & 7,41 & 16,47 & 27,71 & 0,03 & 1,92 & 0,00 & 3,54 \\
\hline 3 & 1 & 1,39 & 0,03 & 1,33 & 1,24 & 1,64 & 13,86 & 0,02 & 4,11 & 0,02 & 1,62 & 3,01 & 16,27 & 0,26 & 2,79 & 0,00 & 0,44 \\
\hline 3 & 8 & 1,06 & 0,00 & 1,76 & 1,03 & 1,44 & 9,57 & 0,00 & 1,30 & 0,00 & 0,94 & 5,38 & 14,95 & 0,61 & 2,19 & 0,00 & 0,15 \\
\hline 3 & 9 & 1,18 & 0,00 & 2,10 & 1,06 & 1,57 & 10,21 & 0,01 & 1,29 & 0,00 & 0,95 & 4,41 & 14,95 & 0,40 & 2,03 & 0,00 & 0,15 \\
\hline
\end{tabular}


TABELA 4: Continuação...

TABLE 4: Continuação...

\begin{tabular}{|c|c|c|c|c|c|c|c|c|c|c|c|c|c|c|c|c|c|}
\hline \multirow[t]{2}{*}{ MB } & Ativ & $\mathrm{Ca}$ & $\mathrm{Cu}$ & $\mathrm{Fe}$ & $\mathrm{K}$ & $\mathrm{Mg}$ & $\mathrm{Na}$ & $\mathrm{P}$ & $\mathrm{S}$ & $\mathrm{Zn}$ & CI & $\mathrm{CO}$ & Clor & Nitr & Sulf & Fosf & Amo \\
\hline & \multicolumn{17}{|c|}{ 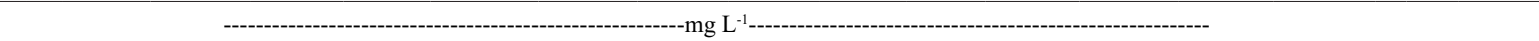 } \\
\hline 3 & 10 & 1,16 & 0,00 & 1,91 & 0,98 & 1,42 & 9,64 & 0,00 & 1,06 & 0,00 & 1,74 & 5,74 & 14,15 & 0,37 & 1,75 & 0,00 & 1,10 \\
\hline 3 & 11 & 1,39 & 0,03 & 0,62 & 0,96 & 1,74 & 10,98 & 0,02 & 2,03 & 0,04 & 0,20 & 22,67 & 17,62 & 0,32 & 1,88 & 0,00 & 0,16 \\
\hline 3 & 12 & 1,27 & 0,02 & 0,82 & 0,91 & 1,60 & 12,09 & 0,01 & 1,98 & 0,00 & 0,04 & 41,07 & 18,86 & 0,27 & 3,55 & 0,00 & 0,13 \\
\hline 3 & 13 & 1,20 & 0,03 & 0,45 & 0,95 & 1,49 & 11,41 & 0,01 & 3,21 & 0,00 & 1,13 & 4,20 & 16,37 & 0,36 & 2,47 & 0,00 & 2,03 \\
\hline 3 & 15 & 1,55 & 0,02 & 2,66 & 1,49 & 1,89 & 13,65 & 0,00 & 2,00 & 0,02 & 2,76 & 2,63 & 22,44 & 0,31 & 3,00 & 0,00 & 0,43 \\
\hline 4 & 1 & 2,58 & 0,02 & 11,4 & 1,44 & 1,74 & 10,32 & 0,00 & 3,02 & 0,02 & 3,29 & 3,49 & 11,35 & 0,07 & 1,05 & 0,00 & 0,32 \\
\hline 4 & 7 & 0,67 & 0,00 & 2,63 & 0,57 & 0,70 & 4,60 & 0,00 & 1,18 & 0,00 & 0,92 & 7,53 & 7,60 & 0,20 & 1,71 & 0,00 & 0,10 \\
\hline 4 & 14 & 2,24 & 0,01 & 7,60 & 0,96 & 1,77 & 8,85 & 0,00 & 1,74 & 0,02 & 3,94 & 4,57 & 12,48 & 0,00 & 1,35 & 0,00 & 0,13 \\
\hline 4 & 5 & 1,70 & 0,02 & 3,15 & 1,05 & 1,41 & 7,38 & 0,00 & 2,27 & 0,00 & 3,04 & 2,60 & 9,63 & 0,09 & 1,85 & 0,00 & 0,19 \\
\hline \multicolumn{2}{|c|}{ Limite } & $400^{2}$ & $0,009^{1}$ & $0,3^{1}$ & $2,0^{2}$ & $60,0^{2}$ & $68,94^{2}$ & $0,03^{1}$ & ----- & $0,18^{1}$ & ----- & ---- & $250^{1}$ & $10^{1}$ & $250^{1}$ & $2,0^{2}$ & $3,7^{1}$ \\
\hline \multicolumn{2}{|l|}{1} & 1 & $<0,01$ & 4,31 & 0,07 & 20,67 & 18,68 & 0,18 & 7,54 & 3,87 & 2,5 & 38,5 & $<0,01$ & 25,3 & 4,44 & 5,73 & 0,00 \\
\hline \multicolumn{2}{|l|}{1} & 2 & $<0,01$ & 4,75 & 0,08 & 8,03 & 1,57 & 1,97 & 8,87 & 4,40 & 1,0 & 49,0 & $<0,01$ & 25,2 & 1,49 & 6,02 & $15,24^{3}$ \\
\hline \multicolumn{2}{|l|}{1} & 3 & $<0,01$ & 4,40 & 0,07 & 14,13 & 10,26 & 1,90 & 7,89 & 3,75 & 6,0 & 20,0 & $<0,01$ & 25,7 & 3,79 & 6,02 & 3,05 \\
\hline \multicolumn{2}{|l|}{1} & 4 & $<0,01$ & 5,36 & 0,07 & 14,63 & 71,63 & 1,82 & 7,75 & 4,11 & 4,0 & 56,0 & $<0,01$ & 24,1 & 4,95 & 6,07 & $30,48^{3}$ \\
\hline \multicolumn{2}{|l|}{2} & 1 & $<0,01$ & 4,98 & 0,11 & 94,83 & 52,13 & 6,14 & 13,94 & 0,37 & 15,0 & 158 & $<0,01$ & 24,0 & 87,70 & 5,55 & 0,00 \\
\hline \multicolumn{2}{|l|}{2} & 5 & $<0,01$ & 5,87 & 0,14 & 217,49 & 60,40 & 6,13 & 14,23 & 0,61 & 9,0 & 87,0 & $<0,01$ & 23,9 & 4,86 & 5,90 & $24,38^{3}$ \\
\hline \multicolumn{2}{|l|}{2} & 4 & $<0,01$ & 4,82 & 0,11 & 207,80 & 75,38 & 2,44 & 12,39 & 0,65 & 11,0 & 82,0 & $<0,01$ & 25,1 & 6,62 & 5,88 & $42,67^{3}$ \\
\hline \multicolumn{2}{|l|}{2} & 6 & $<0,01$ & 7,49 & 0,11 & 188,84 & 4,61 & 6,28 & 13,70 & 0,21 & 15,0 & 63,0 & $<0,01$ & 23,3 & 12,00 & 6,20 & $42,67^{3}$ \\
\hline \multicolumn{2}{|l|}{2} & 7 & $<0,01$ & 21,88 & 0,14 & 152,11 & 59,49 & 10,55 & 15,11 & 0,60 & 18,0 & 56,0 & $<0,01$ & 25,1 & 25,3 & 6,32 & $9,14^{3}$ \\
\hline \multicolumn{2}{|l|}{3} & 1 & $<0,01$ & 4,91 & 0,08 & 28,52 & 28,85 & 3,47 & 6,74 & 6,10 & 8,0 & 68,0 & $<0,01$ & 27,0 & 7,19 & 6,54 & 0,00 \\
\hline \multicolumn{2}{|l|}{3} & 8 & NR & 5,54 & 0,07 & 11,36 & 30,56 & 2,66 & 5,95 & NR & 5,0 & 81,0 & NR & NR & 18,30 & 6,45 & $60,96^{3}$ \\
\hline \multicolumn{2}{|l|}{3} & 9 & $<0,01$ & 7,07 & 0,07 & 33,01 & 16,19 & 2,94 & 6,46 & NR & 2,0 & 63,0 & NR & NR & 13,00 & 6,58 & 6,10 \\
\hline \multicolumn{2}{|l|}{3} & 10 & $<0,01$ & 5,66 & 0,07 & 18,81 & 15,88 & 2,90 & 5,86 & 3,88 & 4,0 & 30,0 & NR & 25,7 & 9,31 & 6,78 & $45,72^{3}$ \\
\hline \multicolumn{2}{|l|}{3} & 11 & $<0,01$ & 6,41 & 0,08 & 3,47 & 9,43 & 3,47 & 7,17 & 5,56 & 3,0 & 48,0 & $<0,01$ & 29,2 & 7,63 & 6,25 & $15,24^{3}$ \\
\hline \multicolumn{2}{|l|}{3} & 12 & $<0,01$ & 6,39 & 0,08 & 25,02 & 8,83 & 3,16 & 6,58 & 6,88 & 3,0 & 31,0 & $<0,01$ & 31,1 & 6,38 & 6,39 & 3,05 \\
\hline \multicolumn{2}{|l|}{3} & 13 & $<0,01$ & 6,05 & 0,08 & 13,62 & 8,05 & 2,99 & 6,12 & 7,60 & 3,0 & 78,0 & $<0,01$ & 28,6 & 7,66 & 6,39 & $30,48^{3}$ \\
\hline \multicolumn{2}{|l|}{3} & 15 & $<0,01$ & 6,70 & 0,09 & 15,81 & 10,25 & 3,87 & 7,78 & 2,60 & 4,0 & 36,0 & $<0,01$ & 23,8 & 8,66 & 5,95 & 9,143 \\
\hline \multicolumn{2}{|l|}{4} & 1 & $<0,01$ & 6,53 & 0,06 & 20,78 & 8,78 & 6,43 & 7,18 & 4,50 & 60,0 & 18,0 & $<0,01$ & 25,9 & 66,5 & 6,70 & 0,00 \\
\hline \multicolumn{2}{|l|}{4} & 7 & $<0,01$ & 1,62 & 0,04 & 26,76 & 26,61 & 1,67 & 2,88 & 2,66 & 13,0 & 89,0 & $<0,01$ & 25,8 & 66,50 & 5,33 & $56,88^{3}$ \\
\hline \multicolumn{2}{|l|}{4} & 14 & $<0,01$ & 14,00 & 0,07 & 57,37 & 9,44 & 5,60 & 7,29 & 5,80 & 25,0 & 66,0 & $<0,01$ & 23,3 & 34,50 & 6,47 & 7,11 \\
\hline 4 & & 5 & $<0,01$ & 6,62 & 0,05 & 34,75 & 13,15 & 4,24 & 5,82 & 4,00 & 25,0 & 40,0 & $<0,01$ & 23,0 & 29,5 & 6,07 & $12,19^{3}$ \\
\hline Limi & & & $0,065^{1}$ & ------ & $0,7^{2}$ & $75,0^{1}$ & ------ & ------ & ------ & $5,0^{1}$ & ----- & $500^{1}$ & ------- & ------ & $100,0^{1}$ & $6-9^{1}$ & ------- \\
\hline
\end{tabular}

Em que: $\mathrm{MB}=$ Microbacia hidrográfica; Ativ $=$ Atividade monitorada pela coleta; ${ }^{1}$ Valor limite estabelecido pelo CONAMA 357/05 para classe 2; ${ }^{2}$ Valor limite estabelecido por Ayres e Westcot (1994). ${ }^{3}$ Valores de intensidade máxima de precipitação (IP) acima da condutividade hidráulica para cada microbacia sob solo saturado (ambos em $\mathrm{mm} \mathrm{h}^{-1}$ ), medida em intervalos de 5 minutos. $\mathrm{NR}=$ Amostragem não realizada.

A concentração dos agrotóxicos glifosato e sulfluramida permaneceram abaixo dos limites de detecção $\left(0,01 \mathrm{mg} \cdot \mathrm{L}^{-1}\right)$ dos métodos empregados durante todo o período de monitoramento. Sendo assim, estas variáveis não foram empregadas na matriz de correlação. Provavelmente, em função do comportamento destes princípios ativos no ambiente, bem como da forma como são utilizados no manejo da cultura do eucalipto, sejam os principais motivos para a falta de detecção destes agrotóxicos nas análises de qualidade da água. O glifosato é um herbicida de largo espectro, não seletivo e de pós-emergência, que apresenta elevada eficiência na eliminação de ervas daninhas (AMARANTE JUNIOR et al., 2002). Na cultura do eucalipto, sua aplicação é feita em pós-emergência, em pleno estágio vegetativo das espécies espontâneas, nas entrelinhas, 
após a implantação ou, ainda, no pré-plantio, para garantir a eliminação da vegetação da área. Sua aplicação costuma variar de acordo com a intensidade e variedades das plantas invasoras (AMARANTE JUNIOR et al., 2002). Estudos demonstram que em solos do tipo argissolo vermelho-amarelo com textura média, a meia-vida do glifosato é de apenas 8 a 9 dias, sendo que não houve influência do histórico de uso do produto (GALLI; MONTEZUMA, 2005). Galli e Montezuma (2005) ainda observaram que em latossolo argiloso, no qual a meia-vida do produto foi de 12 dias sem aplicação prévia de glifosato e de 22 dias no mesmo solo, após 11 anos de aplicação do produto. Apesar de que a meia-vida tenha mostrado pequena variação no solo com o histórico de aplicação do produto, a persistência do glifosato nas condições de solos tropicais em geral é muito curta (ARAÚJO et al., 2003). Quando no ambiente, o glifosato tende a ser inativo quando adsorvido pelo solo (AMARANTE JUNIOR et al., 2002). O composto livre no solo é degradado rapidamente pelo dióxido de carbono através da atividade microbiana (GALLI; MONTEZUMA, 2005).

A sulfluramida $\left(\mathrm{C}_{10} \mathrm{H}_{6} \mathrm{~F}_{17} \mathrm{NSO}_{2}\right)$ pertence ao grupo químico das sulfonas fluoralifáticas e constitui um inibidor da respiração celular dos insetos (CASARIN et al., 2009). Esse princípio ativo é utilizado na forma de isca para o combate às formigas-cortadeiras, especialmente as das espécies dos gêneros Atta e Acromyrmex, que são consideradas as principais pragas de reflorestamentos no Brasil (ZANETTI et al., 2003). Em relação ao uso de sulfluramida, cabe ressaltar que a aplicação deste agrotóxico na forma de isca, em baixa concentração ( $0,3 \%$ do princípio ativo), em pequenas dosagens e de forma esporádica, são os principais motivos do baixo risco de carreamento para o curso de água.

De forma similar ao observado para os agrotóxicos, o fosfato também não foi detectado em nenhuma das amostras. Sabe-se que este íon é pouco móvel em solo tropical e que as dosagens empregadas no manejo são calculadas de acordo com a demanda da cultura e carências deste elemento no solo. Além disso, existem evidências do papel das florestas das áreas de preservação permanente quanto à retenção do íon e diminuição do escoamento superficial, o que reduz o risco de contaminação dos recursos hídricos (SILVA et al., 2001; MCKERGOW et al., 2003).

Quando se comparam as concentrações das variáveis com a resolução CONAMA 357/05 para rios classe 2, é possível verificar que algumas variáveis se encontram fora do limite estabelecido e apresentam-se em destaque na Tabela 4. Destacam-se dentre essas variáveis, o Cu, Fe, P, Cor, OD e pH. As altas concentrações do elemento cobre $(\mathrm{Cu})$ também foram evidenciadas por Campello et al. (2005) quando buscavam verificar se as atividades existentes no entorno de uma unidade de conservação, afetavam os cursos de água do parque da Floresta Nacional de São Francisco de Paula no Rio Grande do Sul. Para os referidos autores, as elevadas concentrações podem ser contribuições do próprio solo ou de fontes clandestinas de despejos de efluentes.

Quanto aos teores de ferro ( $\mathrm{Fe}$ ) foi detectada uma elevada concentração desse elemento para todas as coletas realizadas, sem exceção. Câmara e Lima (1999) detectaram o mesmo quando buscavam evidenciar os efeitos das atividades florestais, sobre a hidrologia da microbacia experimental do Tinga, em São Paulo. Os autores supracitados atribuíram tal aspecto às características dos solos da MB estudada, classificados como Latossolos vermelho-escuro e vermelho-amarelo. No presente estudo, os solos foram classificados como Argissolo Amarelo e Latossolo Amarelo, entretanto, pode-se considerar válida a citação dos autores por não ter outra fonte de contribuição a essa variável a não ser a dos solos.

A concentração de fósforo (P) apresentou-se em desacordo com a legislação $(>0,03 \mathrm{mg} \mathrm{L}-1$ para ambientes lênticos) apenas na microbacia 2 na atividade 7 (colheita) no início do inverno, época com decréscimo nos eventos pluviométricos. Andrade et al. (2008) também encontraram altos teores de P em áreas de floresta, principalmente na época de estiagem. Estes autores citam que essa elevada concentração pode estar possivelmente associada ao acúmulo de material orgânico como folhas, galhos e troncos no leito do curso d'água dessas microbacias. A opinião exposta pelos autores, faz sentido, ao passo que a MB 2 foi a que apresentou maiores resultados de CO, variável indicadora de matéria orgânica. Guimarães et al. (2010) avaliando os impactos da atividade de silvicultura sobre a qualidade dos recursos hídricos superficiais, encontraram concentrações de fósforo total iguais ou acima do limite $\left(>0,1 \mathrm{mg} \mathrm{L}^{-1}\right)$ para ambientes lóticos classe 1 em pelo menos uma das amostragens realizadas, inclusive nas áreas com influência predominante de mata nativa, o que pode estar relacionado com o material orgânico provido da própria vegetação ciliar.

A variável cor apresentou-se acima do limite da legislação apenas na MB 2 durante todo o período monitorado, inclusive na coleta de referência. De acordo com Von Sperling (2005), os sólidos dissolvidos (como pôde ser observado maiores médias na MB 2) interferem também na coloração das 
águas, principalmente em microbacias agrícolas.

O OD apresentou-se abaixo do limite da legislação na maioria das amostragens observadas. Tal fato também foi observado por Guimarães et al. (2010) quando investigavam os impactos da atividade da silvicultura sobre a qualidade da água. Para Carvalho, Schlittler e Tornisielo (2000), a alta concentração de matéria orgânica aliado a baixas velocidades do curso d'água pode levar ao maior consumo de oxigênio do meio. Isso pode ser observado na MB 2 que possui na média as maiores taxas de $\mathrm{CO}$ e menores concentrações de OD, além de possuir características lênticas. Maiores concentrações de matéria orgânica (MO) expressas em Carbono Orgânico (CO) em áreas eucalipto também foram encontrados por Bueno (2005), todavia, deve-se levar em consideração também, o efeito das APPs sobre a contribuição da MO da água.

$\mathrm{O}$ pH também apresentou concentrações fora dos limites estabelecidos pela legislação, em pelo menos uma amostragem de cada microbacia. Tal fato também foi constatado por Guimarães et al. $(2008 ; 2010)$ e pode ser ocasionado pela acidez natural dos solos das microbacias, como pode ser observado na Tabela 2.

\section{Efeito das atividades silviculturais e das intensidades de precipitação ocorridas}

Comparando as alterações das variáveis de qualidade da água da amostragem de referência (Atividade 1) com as demais amostragens que representam as atividades desenvolvidas nas MBs, verifica-se por meio da Tabela 4 que na MB 1 as variáveis Ferro, CO, clor, Sulf e SS apresentaram concentrações superiores aos da referência na atividade 3 (limpeza de cepas e primeiro combate a formiga). Já as variáveis $\mathrm{S}, \mathrm{CI}$, Alca e DQO tiveram maiores concentrações na atividade 4 (primeiro combate à formiga), enquanto que apenas a dureza de cálcio apresentou maior concentração para atividade 2 (abertura de estrada, colheita e transporte), mas não muito superior aos apresentados nas atividades 3 e 4. Para alguns autores (LIMA, 1993; ALVES; CASTRO, 2003; BRAGA et al., 2005; VON SLERLING, 2005), as alterações da concentração das variáveis de qualidade da água podem estar relacionadas ao processo natural das águas da microbacia, afinal, as atividades monitoradas $(2,3$ e 4$)$ nessa $\mathrm{MB}$ não possuem meios que possam contribuir para a variação de tais variáveis.

Na MB 2, analisando os resultados encontrados aos da referência, observa-se que as variáveis ferro, CI, amônia e alcalinidade apresentaram maiores concentrações para a atividade 7 (colheita). As elevadas concentrações do elemento ferro, após o corte do eucalipto, também foram observadas por Câmara e Lima (1999) e Grayson et al. (1993). Segundo estes autores, o aumento na concentração dessas variáveis pode estar associado ao transporte de substâncias húmicas, derivadas da decomposição da biomassa que permaneceu sobre o solo após a colheita. Entretanto, é importante salientar, que como as áreas de preservação permanentes às margens dos cursos d'água dessas microbacias são conservadas, esse transporte pode ter acontecido mais subsuperficialmente do que, efetivamente por escoamento superficial, como ponderam alguns autores (MCKERGOW et al., 2003; LIMA, 2008; BARROS et al., 2010).

Na MB 3 foram evidenciadas maiores concentrações para as variáveis ferro, CI e Cloreto na atividade 15 (adubação de terceiro mês) quando comparada às demais amostragens e de referência. A adubação de terceiro mês contendo N-P-K pode ter contribuído para a elevação da concentração de algumas variáveis, como por exemplo, o cloreto. Contudo, neste estudo, não foi possível encontrar evidências suficientes que a comprovasse, pois seria necessário analisar estas variáveis na água subterrânea e de escoamento superficial, o que pode não ter chegado a contribuir por estas formas, como já discutido anteriormente.

Na MB 4 observou-se maiores concentrações para as variáveis CO, DQO, SD eturbidezna amostragem da atividade 7 (colheita). Os resultados encontrados nessa MB para as variáveis SD e turbidez corroboram a colocação de alguns autores, como já relatado anteriormente, que citam que a atividade de colheita pode auxiliar no aumento de algumas variáveis relacionadas aos sólidos na água (GRAYSON et al., 1993; LIMA; ZAKIA, 2006; CROKE et al., 1999; ENSIGN; MALLIN et al., 2001; RANZINI; LIMA, 2002). No entanto, é importante lembrar que as atividades 5 (roçada) e 7 (colheita) aconteceram nas MBs 2 e 4, entretanto, não foi possível observar coincidência de elevadas concentrações para as variáveis turbidez e SD nas duas MBs, o que reforça que as variáveis podem ter um comportamento diferente em microbacias sobre o mesmo uso do solo.

A atividade 4 (primeiro combate a formiga) foi desenvolvida nas MBs 1 e 2. Analisando as concentrações das variáveis monitoradas nessas MBs, apenas a DQO apresentou maiores concentrações médias para essa atividade nas duas MBs. As altas concentrações para essa variável na MB 1 e MB 2 podem estar relacionadas ao acúmulo de material orgânico nas águas das MBs, como 
pode ser comprovado nas maiores concentrações de $\mathrm{CO}$ das mesmas. As maiores concentrações de CO pode ser proveniente da vegetação ciliar dessas MBs, não sendo possível, dessa forma, atribuir a alta concentração de $\mathrm{CO}$ às atividades desenvolvidas, pois estas acontecem acima das APPs, que interceptam sedimentos e nutrientes, conforme aponta estudo de McKergow et al. (2003).

Considerando o efeito das atividades de silvicultura nas microbacias, o presente estudo não constatou efeito expressivo sobre as variáveis de qualidade da água. $\mathrm{O}$ impacto das operações silviculturais sobre a qualidade da água foi estudado em duas microbacias hidrográficas na Austrália (GRAYSON et al., 1993), de acordo com este estudo, houve efeito da operação de colheita sobre algumas das variáveis de qualidade da água. Todavia, no presente estudo realizado, não foi observado este mesmo efeito, o que pode estar relacionado com o cultivo mínimo das áreas, tipo de solo e declividade do terreno, com a manutenção dos resíduos de colheita na área, entre outros fatores.

As diferentes intensidades de precipitação (IP) ocorridas nas áreas estudadas não afetaram as concentrações das variáveis quanto à qualidade da água, mesmo quando as intensidades apresentaram acima da condutividade hidráulica dos solos das MBs estudadas (Tabela 4). O observado no presente estudo pode estar relacionado à preservação das áreas de preservação permanente, que têm papel importante na redução do escoamento superficial e no aumento da infiltração de água (SILVA; WILLIAMS, 2001; MCKERGOW et al., 2003; BARROS et al., 2010). O desenvolvimento de florestas na área ripária tem sido considerado importante para melhorar a qualidade da água superficial, funcionando como área tampão (LIMA, 2008). Além disso, acredita-se que a forma de cultivo mínimo, a aplicação sistemática e em baixas concentrações dos fertilizantes e o mosaico de áreas de plantio de eucalipto com as áreas de reserva legal e de preservação permanente tenham contribuído para reduzir o risco de alteração da qualidade da água. Este resultado foi observado mesmo quando as atividades silviculturais foram realizadas em períodos de maior ocorrência de chuvas.

\section{Determinação dos componentes principais para qualidade da água}

A aplicação de componentes principais é uma boa estratégia para reduzir a quantidade de variáveis que normalmente são monitoradas (MOURA et al., 2010). Neste sentido, um modelo composto de quatro componentes foi adequado para representar $73,1 \%$ da variância acumulada no presente estudo, sendo que a primeira componente explicou $31,6 \%$, enquanto a segunda $18,5 \%$, a terceira $15,6 \%$ e, finalmente, a quarta $7,4 \%$ da variância total dos dados (Tabela 5). Com uso deste modelo foi possível reduzir de 30 para 12 variáveis que devem ser monitoradas para definição da qualidade da água em áreas com plantios de eucalipto.

TABELA 5: Análise de componentes principais para determinação da qualidade da água.

TABLE 5: Principal component analysis to determinate the water quality.

\begin{tabular}{ccccc}
\hline \multirow{2}{*}{ Componentes } & Autovalores & Variância unitária (\%) & Autovalores Acumulados & Variância acumulada \\
\hline 1 & 7,905 & 31,622 & 7,905 & 31,622 \\
2 & 4,633 & 18,533 & 12,539 & 50,155 \\
3 & 3,894 & 15,576 & 16,433 & 65,731 \\
4 & 1,843 & 7,371 & 18,276 & 73,102 \\
5 & 1,548 & 6,193 & 19,824 & 79,295 \\
6 & 1,188 & 4,753 & 21,012 & 84,048 \\
7 & 1,103 & 4,412 & 22,115 & 88,461 \\
\hline
\end{tabular}

No sul do Brasil, um modelo de três componentes foi utilizado para explicar 50,8\% da variância das 13 variáveis analisadas (ALMEIDA; SCHWARZBOLD, 2003). De forma similar, no estado do Ceará, região nordeste do Brasil, em outro estudo, em uma bacia hidrográfica com $10.000 \mathrm{~km}^{2}$ com diferentes usos dos solos, foi possível explicar 39,8\% de variância total considerando o primeiro componente, $29,2 \%$ no segundo componente e, mais 19,2\% para o terceiro componente, sendo também possível reduzir de 26 para 16 variáveis analisadas (ANDRADE et al., 2007a). Em outra pesquisa, com o objetivo de classificar as fontes hídricas superficiais na bacia do rio Salitre no estado da Bahia, três componentes explicavam $86,9 \%$ 
e 71,3\% da variância total acumulada, nos períodos de chuvas e de estiagem, respectivamente (BRITO et al., 2006). Do mesmo modo, ao determinar a qualidade da água no rio Jaibaras no Ceará, foi verificado que três componentes atendiam ao objetivo do estudo com $80,2 \%$ de variância total e 37,6\%,30,9\% e 11,8\% de variância unitária para cada um dos três componentes, nessa ordem (GIRÃO et al., 2007).

Vários estudos demonstram que, em determinadas situações, é possível reduzir o número de variáveis para predição da qualidade da água. Por exemplo, um estudo desenvolvido no perímetro irrigado do Baixo Acaraú, no Ceará, empregou-se cinco componentes principais, possibilitando reduzir de 27 para 12 variáveis que deveriam ser monitoradas (LOPES et al., 2009). Em outro estudo, no qual foi possível correlacionar a qualidade da água com o uso e a ocupação do solo na bacia do Gama em Brasília, foi possível reduzir de 24 para 8 variáveis, mantendo $70,9 \%$ de representação da variância dos dados (MOURA et al., 2010).

\section{Determinação dos fatores que mais afetam a qualidade da água}

As comunalidades foram altas para todas as variáveis apresentadas, assim sendo, a maior parte da variância para cada uma das variáveis foi explicada pelos sete componentes comuns. Para determinar as variáveis que mais representam a qualidade da água, descartaram-se os fatores 5, 6 e 7 representados pelas variáveis enxofre (S) e sulfato (Sulf), zinco (Zn) e temperatura (Temp), respectivamente (Tabela 6). De acordo com os resultados, estes fatores têm pouco peso para representar a qualidade da água, uma vez que, a temperatura do curso hídrico é influenciada pela radiação solar e as demais variáveis pela influência dos atributos de química do solo.

TABELA 6: Determinação das correlações das principais variáveis de qualidade da água.

TABLE 6: Determination of correlations of the main water quality variables.

\begin{tabular}{ccccccccc}
\hline Variáveis & $\mathrm{C} 1$ & $\mathrm{C} 2$ & $\mathrm{C} 3$ & $\mathrm{C} 4$ & $\mathrm{C} 5$ & $\mathrm{C} 6$ & $\mathrm{C} 7$ & Comunalidades \\
\hline Clor & 0,935 & $-0,126$ & 0,118 & 0,174 & 0,096 & 0,108 & 0,025 & 0,955 \\
Cor & 0,861 & 0,270 & $-0,152$ & 0,089 & 0,193 & $-0,135$ & $-0,188$ & 0,937 \\
$\mathrm{CE}$ & 0,845 & $-0,039$ & $-0,031$ & 0,351 & 0,340 & 0,133 & $-0,029$ & 0,973 \\
$\mathrm{Mg}$ & 0,767 & 0,002 & $-0,144$ & 0,306 & 0,419 & 0,170 & $-0,233$ & 0,962 \\
$\mathrm{CO}$ & 0,740 & $-0,080$ & $-0,073$ & $-0,351$ & $-0,089$ & 0,187 & 0,123 & 0,740 \\
$\mathrm{Na}$ & 0,733 & $-0,121$ & 0,341 & 0,060 & 0,439 & 0,118 & 0,063 & 0,882 \\
$\mathrm{SS}$ & $-0,225$ & 0,873 & $-0,079$ & 0,199 & 0,105 & 0,121 & $-0,103$ & 0,895 \\
$\mathrm{Fe}$ & $-0,254$ & 0,858 & 0,039 & 0,243 & $-0,088$ & 0,141 & $-0,145$ & 0,909 \\
Nitr & $-0,385$ & $-0,798$ & $-0,164$ & $-0,152$ & 0,084 & 0,189 & $-0,086$ & 0,885 \\
pH & $-0,186$ & 0,252 & 0,735 & 0,304 & 0,037 & 0,051 & 0,241 & 0,792 \\
CI & $-0,088$ & 0,287 & 0,031 & 0,910 & $-0,070$ & $-0,074$ & $-0,173$ & 0,960 \\
Alca & 0,217 & 0,181 & 0,121 & 0,897 & $-0,042$ & 0,091 & $-0,047$ & 0,912 \\
S & 0,171 & 0,132 & 0,001 & 0,055 & 0,926 & $-0,112$ & $-0,063$ & 0,924 \\
Sulf & 0,322 & $-0,100$ & $-0,295$ & $-0,187$ & 0,802 & $-0,174$ & $-0,169$ & 0,938 \\
Zi & 0,148 & 0,034 & 0,131 & $-0,026$ & $-0,190$ & 0,917 & 0,104 & 0,928 \\
Temp & $-0,161$ & $-0,129$ & 0,097 & $-0,143$ & $-0,130$ & 0,109 & 0,882 & 0,880 \\
Autovalores & 6,304 & 3,496 & 2,070 & 3,571 & 2,686 & 1,521 & 2,467 & - \\
Variância (\%) & 25,218 & 13,983 & 8,282 & 14,285 & 10,743 & 6,083 & 9,867 & -
\end{tabular}

Em que: Clor $=$ Cloreto; $\mathrm{CE}=$ Condutividade Elétrica; $\mathrm{CO}=$ Carbono Orgânico; $\mathrm{SS}=$ Sólidos Suspensos; Nitr = Nitrato CI = Carbono Inorgânico; Alca $=$ Alcalinidade; Sulf $=$ Sulfato; Tem $=$ Temperatura .

No primeiro fator $(\mathrm{C} 1)$ destacam-se as altas correlações formadas pelas variáveis $\mathrm{Mg}(0,76), \mathrm{Na}$ $(0,73), \mathrm{CO}(0,74)$, Clor $(0,93), \mathrm{CE}(0,84)$ e Cor $(0,86)$ caracterizando-o como "fator mineral" por expressar maior associação às variáveis indicadoras de enriquecimento por íons solúveis com pesos elevados. Os resultados deste estudo foram semelhantes aos encontrados em avaliações realizadas no nordeste do Brasil, 
com coincidência das variáveis $\mathrm{Mg}$, Na, CE e Clor (ANDRADE et al., 2007a). Em outro estudo, também no nordeste do Brasil, os autores encontram as mesmas variáveis além da dureza expressa pelos carbonatos de cálcio e magnésio, no quarto fator (ANDRADE et al., 2007b). Ainda em estudos no semiárido do nordeste do Brasil, encontrou-se, no primeiro fator, a correlação positiva com o $\mathrm{Ca}^{2+} \mathrm{e} \mathrm{Na}^{2+}$, sendo nomeado como "mineral" devido à mineralização das águas e por ser um fator importante na determinação de sua qualidade (GIRÃO et al., 2007).

O segundo fator $(\mathrm{C} 2)$ correlacionou-se positivamente com as variáveis $\mathrm{Fe}(0,85)$ e SS $(0,87)$ e pode ser caracterizado como "fator sólido". Acredita-se que a presença destes fatores na mesma componente está relacionada ao processo de floculação (COMPANHIA AMBIENTAL DO ESTADO DE SÃO PAULO, 2008). O transporte de sedimentos, refletido nas variáveis cor, turbidez, sólidos suspensos e o $\mathrm{pH}$, foi evidenciado como terceiro fator por outros autores, caracterizando o escoamento superficial das áreas agrícolas e em função do clima (ANDRADE et al., 2007a). Em outro trabalho, o "fator sólido" foi evidenciado como segundo componente, sendo correlacionado com a maior ocorrência de chuvas durante as coletas (ALMEIDA; SCHWARZBOLD, 2003).

No terceiro fator $(\mathrm{C} 3)$, apenas a variável $\mathrm{pH}$ apresentou forte correlação positiva $(0,73)$. Esse fator pode ser denominado como "fator acidez" e possivelmente está relacionado ao $\mathrm{pH}$ dos solos das microbacias. Estudos comprovam que a variação do $\mathrm{pH}$ pode ser considerada um fator sazonal preponderante, representado pela variação na pluviosidade (ALMEIDA; SCHWARZBOLD, 2003).

No quarto fator $(\mathrm{C} 4)$ encontram-se positivamente correlacionadas as variáveis carbono inorgânico $(0,91)$ e alcalinidade $(0,89)$, sendo nomeada como "fator pedológico". Essa denominação é adotada em função dos efeitos dos bicarbonatos $\left(\mathrm{HCO}_{3}^{-}\right)$, carbonatos $\left(\mathrm{CO}_{3}^{2-}\right)$ e hidróxidos $\left(\mathrm{OH}^{-}\right)$sobre a alcalinidade, sendo que os bicarbonatos e carbonatos são os elementos formadores do carbono inorgânico a partir da dissolução de rochas carbonatadas (VON SPERLING, 2005). Essas variáveis podem representar indicadores geoquímicos e físico-químicos (MOURA et al., 2010).

Em geral e de acordo com os resultados obtidos no presente trabalho, os fatores de qualidade da água estão diretamente relacionados com a salinidade, a presença de sólidos suspensos, a acidez e o teor de carbono inorgânico do solo, respectivamente. Estes fatores foram determinantes, independentemente da realização de atividades silviculturas e/ou da ocorrência de chuvas durante a realização do monitoramento.

\section{CONCLUSÕES}

Pelos resultados expostos, é possível concluir que os fatores relacionados ao tempo, como o decréscimo na frequência de precipitação e consequentemente as vazões dos cursos d'água, a preservação das APPs e os solos das microbacias influenciaram, indubitavelmente, mais que as atividades desenvolvidas no interior de cada microbacia monitorada.

De forma geral, quatro componentes foram suficientes para explicar a maior parte da variância total dos dados de qualidade da água. Os componentes foram correlacionados com as variáveis analisadas e definidos como fatores: mineral, sólido, acidez e pedológico. Estes fatores estão diretamente relacionados com a salinidade, a presença de sólidos suspensos, a acidez e o teor de carbono inorgânico do solo, respectivamente. Não foi observada presença dos agrotóxicos sulfluramida (inseticida) e glifosato (herbicida) em todas as avaliações realizadas.

Em geral, é possível reduzir de 30 para 12 as variáveis que devem ser monitoradas para predição da qualidade da água, mantendo pelo menos $70 \%$ da precisão das estimativas. A avaliação dessas variáveischave permite estabelecer um adequado sistema de monitoramento da qualidade de água considerando as atividades de silvicultura do eucalipto.

\section{REFERÊNCIAS}

ASSOCIAÇÃO BRASILEIRA DE NORMAS TÉCNICAS. NBR 9898: preservação e técnicas de amostragem de efluentes líquidos e corpos receptores. Rio de Janeiro, 1987. 22 p.

ALMEIDA, M. A. B.; SCHWARZBOLD, A. Avaliação sazonal da qualidade das águas do Arroio da Cria Montenegro, RS com aplicação de um Índice de Qualidade de Água (IQA). Revista Brasileira de Recursos 
Hídricos, Porto Alegre, v. 8, n. 1, p. 81-97, jan./mar. 2003.

ALVARES, C. A. et al. Köppen's climate classification map for Brazil. Meteorologische Zeitschrift, Stuttgard, v. 22, n. 6, p. 711-728, 2013.

ALVES, J. M. P.; CASTRO, P. T. A. Influência de feições geológicas na morfologia da bacia do rio do tanque (MG) baseada no estudo de parâmetros morfométricos e análise de padrões de lineamentos. Revista Brasileira de Geociências, Curitiba, v. 33, n. 2, p. 117-124, jun. 2003.

AMARANTE JUNIOR, O. P. et al. Glifosato: propriedades, toxicidade, usos e legislação. Química Nova, São Paulo, v. 25, n. 4, p. 589-593, 2002.

ANDRADE, E. M. de. et al. Fatores determinantes da qualidade das águas superficiais na bacia do Alto Acaraú, Ceará, Brasil. Ciência Rural, Santa Maria, v. 37, n. 6, nov./dez., 2007a.

ANDRADE, E. M. et al. Seleção dos indicadores da qualidade das águas superficiais pelo emprego da análise multivariada. Revista Engenharia Agrícola, Jaboticabal, v. 27, n. 3, p. 683-690, set./dez. 2007 b.

ANDRADE, E. M. et al. Índice de qualidade de água, uma proposta para o vale do rio Trussu, Ceará. Revista de Ciência Agronômica, Fortaleza, v. 36, n. 2, p. 135-142, maio/ago. 2005.

ANDRADE, N. L. R. et al. Macro-nutrientes no lençol freático em Floresta Intacta, Floresta de Manejo e Pastagem no norte de Mato Grosso. Acta Amazonica, Manaus, v. 38, n. 4, p. 667-672, 2008.

AMERICAN PUBLIC HEALTH ASSOCIATION. Standard Methods for the Examination of Water and Wastewater. 21 st ed. [s.1]: APHA, 2005.

ARAÚJO, A. S. F. et al. Effect of glyphosate on the microbial activity of two Brazilian soils. Chemosphere, Los Angeles, v. 52, p. 799-804, 2003.

BARROS, Y. J. et al. Influência de diferentes usos e ocupações do solo na qualidade da água dos igarapés Piarara e Tamarupá, em Cacoal - RO. Revista de Ciências Agrárias, Manaus, v. 1, n. 53, p. 102-107, jan./ jun. 2010.

BRAGA, B. et al. Introdução à engenharia ambiental. 2. ed. São Paulo: Pearson Prentice Hall, 2005. $318 \mathrm{p}$.

BRITO, L. T. L. et al. Uso de análise multivariada na classificação das fontes hídricas subterrâneas da bacia hidrográfica do Salitre. Engenharia Agrícola, Jaboticabal, v. 26, n. 1, p. 36-44, 2006.

BUENO, L. F. et al. Monitoramento de variáveis de qualidade da água do Horto Ouro Verde, Conchal, SP. Engenharia Agrícola, Jaboticabal, v. 25, n. 3, p. 742-748, set./dez. 2005.

CÂMARA, C. D.; LIMA, W. L. Corte raso de uma plantação de Eucalyptus saligna de 50 anos: impactos sobre o balanço hídrico e a qualidade da água em uma microbacia experimental. Scientia Foretalis, Piracicaba, n. 56, p. 41-58, dez. 1999.

CAMPELLO, F. D. et al. Avaliação preliminar da qualidade das águas da Floresta Nacional de São Francisco de Paula, RS, Brasil. Revista Brasileira de Biociências, Porto Alegre, v. 3, n. 1, p. 9-46, jan./dez. 2005.

CARVALHO, A. P.; SCHLITTLER, F. H. M.; TORNISIELO, V. L. Relação da atividade agropecuária com parâmetros físico-químicos da água. Química Nova, São Paulo, v. 23, n. 5, 2000.

CASARIN, F. E. et al. Avaliação em Laboratório dos Ingredientes Ativos Sulfluramida e Hidrametilnona para o Controle do Cupim Subterrâneo Coptotermes gestroi (Wasmann) (Isoptera: Rhinote rmitidae). Revista Brasileira de Zoociências, Juiz de fora, v. 11, n. 3, p. 219-226, 2009.

COMPANHIA AMBIENTAL DO ESTADO DE SÃO PAULO. Significado ambiental e sanitário das variáveis de qualidade das águas e dos sedimentos e metodologias analíticas de amostragem. São Paulo: Secretaria de Meio Ambiente, Governo do Estado de São Paulo, 2008. (Apêndice A, Série de relatórios).

CROKE, J. et al. Managing sediment sources and movement in forests: the forest industry and water quality. [s. 1.]: Cooperative Research Centre for Catchment Hydrology, 1999. (Séries: Report).

EMBRAPA. Centro de Pesquisa de solos. Levantamento generalizado e semidetalhado de solos da Aracruz Celulose S. A. no Estado do Espírito Santo e no Extremo sul do Estado da Bahia e suas aplicações aos plantios de eucalipto. Rio de Janeiro: Embrapa Solos, 2000. 93 p.

ENSIGN, S. H.; MALLIN, M. A. Stream water quality changes following timber harvest in a coastal plain swamp forest. Water Research, Los Angeles, v. 35, n. 14, p. 3381-3390, 2001.

GALLI, A. J. B.; MONTEZUMA, M. C. Glifosato: alguns aspectos da utilização do herbicida na agricultura. São Paulo: ACADCOM, 2005. 67 p.

GIRÃO, E. G. et al. Seleção dos indicadores da qualidade de água no Rio Jaibaras pelo emprego da análise 
da componente principal. Revista Ciência Agronômica, Fortaleza, v. 38, n. 1, p. 17-24, 2007.

GRACE, J. M. Forest operations and water quality in the south. American Society of Agricultural Engineers, Josep, v. 48, n. 2, p. 871-880, 2005.

GRAYSON, R. B. et al. Water quality in mountain ash forests - separating the impacts of roads from those of logging operations. Journal of Hydrology, Amsterdam, v. 150, p. 459-480, 1993.

GUIMARÃES, R. Z. et al. A silvicultura e os recursos hídricos superficiais. Pesquisa Florestal Brasileira, Colombo, n. 56, p. 79-85, jan./jun. 2008.

GUIMARÃES, R. Z. et al. Avaliação dos impactos da atividade de silvicultura sobre a qualidade dos recursos hídricos superficiais. Scientia Forestalis, Piracicaba, v. 38, n. 87, p. 377-390, set. 2010.

HAIR JUNIOR, J. F. et al. Análise multivariada de dados. 5. ed. Porto Alegre: Bookman, 2009. 688 p.

LIMA, W. P. Hidrologia florestal aplicada ao manejo de bacias hidrográficas. São Paulo: USP, 2008. $244 \mathrm{p}$.

LIMA, W. P.; ZAKIA, M. J. B. As florestas plantadas e a água: implementando o conceito da microbacia hidrográfica como unidade de planejamento. São Carlos: Rima, 2006. 226 p.

LOPES, F. B. et al. Proposta de um índice de sustentabilidade do Perímetro Irrigado Baixo Acaraú, Ceará, Brasil. Revista Ciência Agronômica, Fortaleza, v. 40, n. 2, p. 185-193, abr./jun, 2009.

MCKERGOW, L. A. et al. Before and after riparian management: sediment and nutrient exports from a small agricultural catchment, Western Australia. Journal of Hydrology, Amsterdam, v. 27, p. 253-272, 2003.

MENEZES, M. D. et al. Dinâmica hidrológica de duas nascentes, associada ao uso do solo, características pedológicas e atributos físicos-hídricos na sub-bacia hidrográfica do Ribeirão Lavrinha-Serra da Mantiqueira (MG). Scientia Forestalis, Piracicaba, v. 37, n. 82, p. 175-184, 2009.

MOURA, L. H. A. et al. A qualidade de água como indicador de uso e ocupação do solo: bacia do Gama Distrito Federal. Química Nova, São Paulo, n. 33, n. 1, p. 97-103, 2010.

RANZINI, M.; LIMA, W. P. Comportamento hidrológico, balanço de nutrientes e perdas de solo em duas microbacias reflorestadas com Eucalyptus, no Vale do Paraíba, SP. Scientia Forestalis, Piracicaba, n. 61, p. 144-159, jun. 2002.

SCHELKER, J. et al. Effects of forestry operations on dissolved organic carbon concentrations and export in boreal first-order streams. Journal of Geophysical Research, New Zealand, v. 117, 2012.

SILVA, L.; WILLIAMS, D. D. Buffer zone versus whole catchment approaches to studying land use impact on river water quality. Water Research, Los Angeles, v. 35, n. 14, p. 3462-3472, 2001.

VON SPERLING, M. Princípios do tratamento biológico de águas residuárias: introdução à qualidade das águas e ao tratamento de esgotos. 3. ed. Belo Horizonte: UFMG, 2005. v. 1. 452 p.

ZANETTI, R. et al. Combate sistemático de formigas-cortadeiras com iscas granuladas, em eucaliptais com cultivo mínimo. Revista Árvore, Viçosa, MG, v. 27, n. 3, p. 387-393, 2003. 